\title{
Histology of pterygium: an electron microscopic study
}

\author{
MALCOLM E. CAMERON \\ From the Brisbane Clinic, Brisbane, Queensland, Australia
}

SUMMARY An electron microscopic study of the cap areas of several pterygia shows the presence of active fibroblasts in the natural tissue planes surrounding Bowman's layer. The hypothesis is advanced that the fibroblasts originate in the limbal connective tissue. They advance in the cornea above and below Bowman's membrane, destroying the latter and a variable amount of superficial corneal stroma.

The following electron microscopic study of the histology of the cap area of the pterygium was undertaken as a follow-up to the author's previous studies by light microscopy. In this study' ${ }^{1}$ it was shown that there were fibroblasts growing centripetally along natural tissue planes destroying Bowman's layer and a variable amount of the superficial cornea. The theory was put forward that a pterygium was brought about by the ingrowth of fibroblasts from the subconjunctival tissue of the limbus into the adjoining cornea.

In support of this view Cameron with numerous photomicrographs showed fibroblasts appearing to invade the cornea on either side of Bowman's layer. Similar photomicrographs have been published by other observers. For example, compare Fig. 1 of Cilova-Antanasova's article ${ }^{2}$ with Fig. 58 in Cameron's monograph ${ }^{1}$ and Fig. 8 of Barraquer's ${ }^{3}$ article with Fig. 59 (c) in Cameron's monograph. ${ }^{1}$ Both Cllova-Atanasova and Barraquer show the alterations in the basal epithelium of the cornea, Bowman's layer, and the superficial corneal lamellae but consider that these have been produced by metabolic changes ${ }^{2}$ or by chronic corneal ulceration. ${ }^{3}$ Other workers ${ }^{4-8}$ have concentrated their attention on the degenerated elastic and collagen fibres in the base of the pterygium.

A recent electron microscopic study ${ }^{9}$ describes hyaline degeneration and elastosis but also changes in the fibroblasts, endothelial cells, pericytes, and the basement membrane of conjunctival capillaries and small veins. They believe that chronic exposure to the sun damages the endothelial cells of the conjunctival

Correspondence to Dr M. E. Cameron, Brisbane Clinic, 79 Wickham Terrace, Brisbane, Queensland, Australia. capillaries. This in turn disturbs the metabolism of the fibroblasts, with alteration of the collagen and elastic fibres.

There is thus sufficient diversity of opinion to warrant yet another attempt at studying the histology of the pterygium. Most of the studies already quoted were by light microscopy, with the exception of those by van der Zypen et al., ${ }^{6}$ Hogan and Alvarado, ${ }^{5}$ and Lemercier et al., which were by electron microscopy.

\section{Materials and methods}

Pterygia were surgically removed, placed on a card to facilitate orientation, and fixed by immersion in a $3 \%$

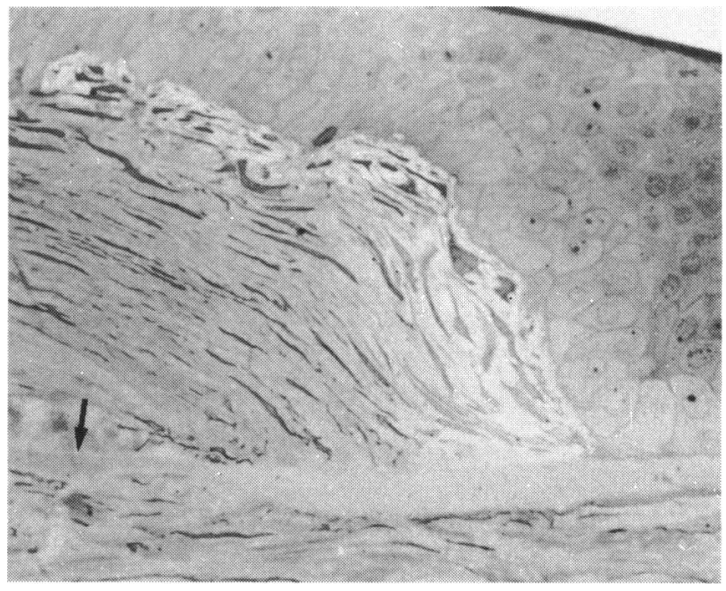

Fig. 1 The basal cell layer of the cornea is separated from Bowman's layer by a wedge-shaped mass of fibroblasts. The remains of Bowman's layer are arrowed. (Phase contrast, $\times 310)$. 


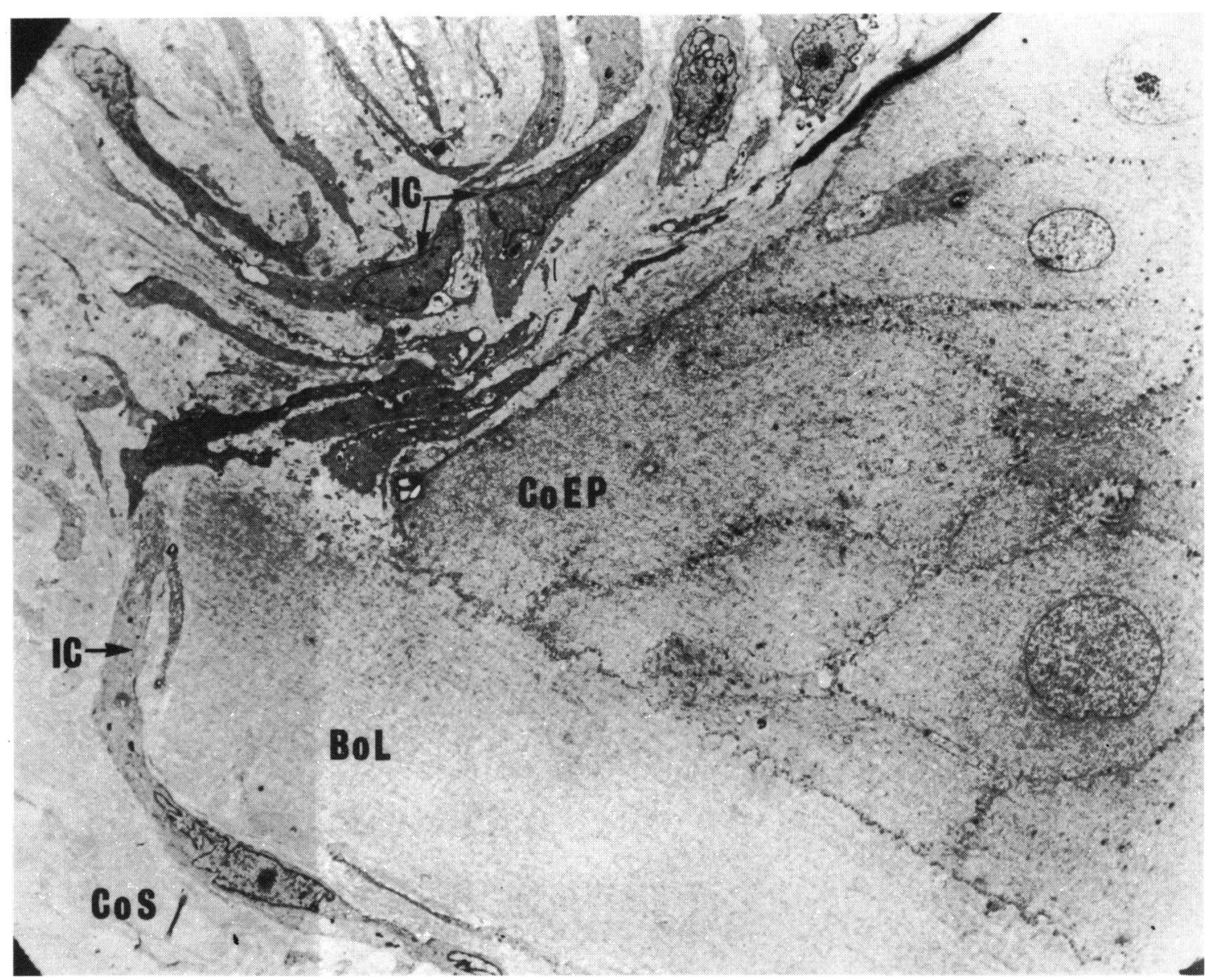

Fig. 2 Electron micrograph showing fibroblasts (IC) adjacent to the basal cell layer of the corneal epithelium (CoEP) and Bowman's layer $(\mathrm{BoL})$. Another fibroblast with a well marked nuclear envelope and prominent nucleolus is between Bowman's layer and the superficial corneal stroma $(\mathrm{CoS}) .(\times 1480)$.

cacodylate buffered glutaraldehyde solution ( $\mathrm{pH} 7 \cdot 2$ ) for 2 hours. After an overnight wash in cacodylate buffer, blocks of tissue were postfixed in osmium tetroxide, stained en bloc in 5\% aqueous uranyl acetate, dehydrated in ethanol, and embedded in Epon 812. Ultrathin sections were cut on an LKB Ultratome III, stained with lead citrate, and examined in a Zeiss EM 9S electron microscope.

\section{Results}

The basal cell layer of the corneal epithelium was separated from Bowman's layer by a wedge of fibroblastic tissue. The basal cells were not greatly altered by the process, but they were elevated and their normal vertical axes had become oblique. Bowman's layer and variable amount of the superficial corneal stroma on the other hand were severely affected (Fig. 1).

The fibroblasts were found in the area of tissue destruction and could be seen to be closely applied to the edge of Bowman's layer, which was partly destroyed. Their nuclei were elongated and irregular, with numerous nuclear pores (Fig. 2).

The basal cell membrane and basement membrane of the corneal epithelium were well preserved even though they did not rest on normal Bowman's layer (Fig. 3).

Immediately central to the cap of the pterygium the basal cell membrane, basement membrane, and Bowman's layer appeared normal (Fig. 4).

\section{Discussion}

The above electron microscopy study shows similar 
Fig. 3 Well preserved basal cell membrane with intact hemidesmosomes. The basement membrane appears intact in places. Below it are masses of collagen fibres and several fibroblasts. $A$ linear area of elastosis is arrowed. $(\times 4070)$.

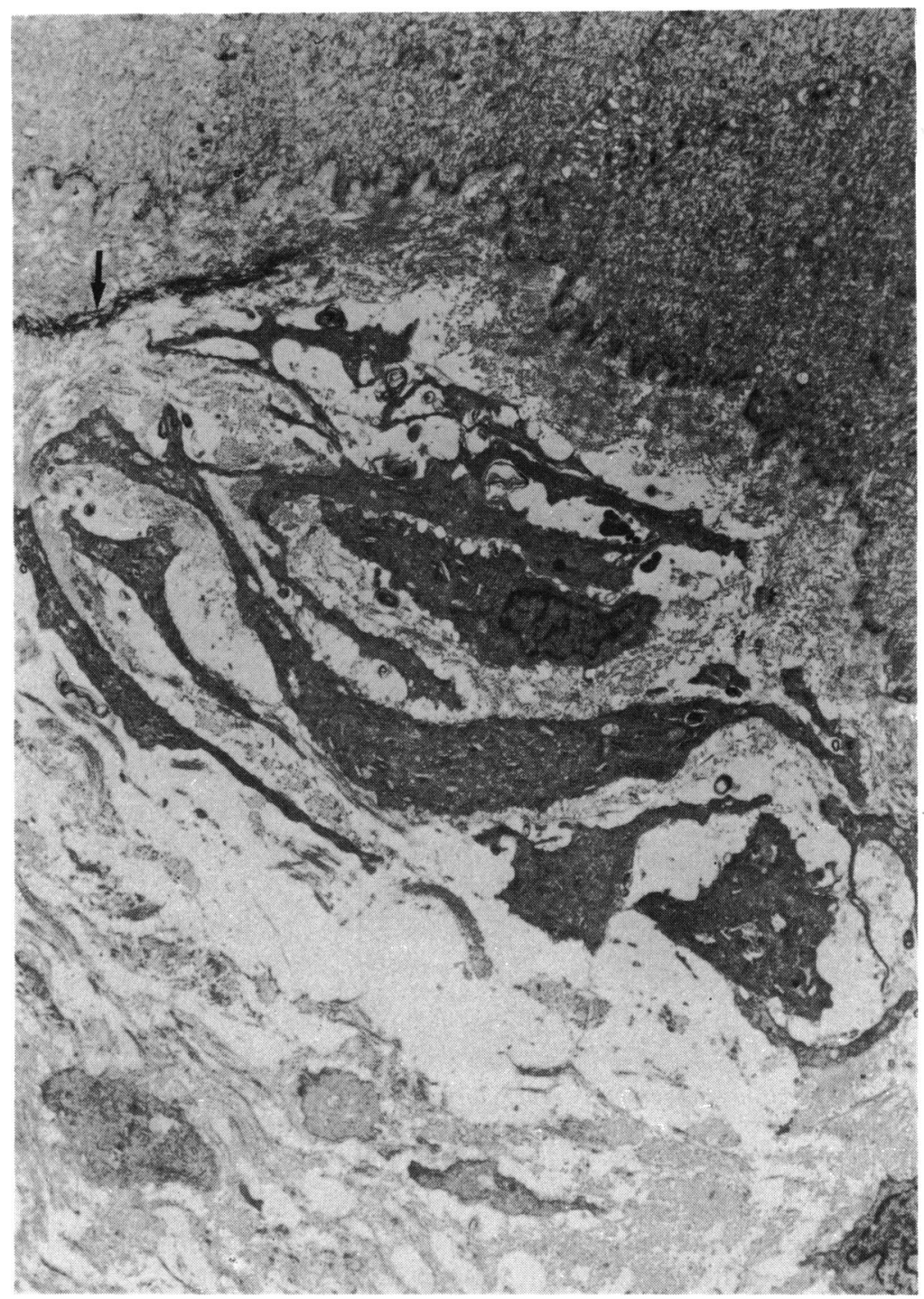

changes to those previously observed by Cameron ${ }^{1}$ and suggests that a pterygium could be due to an invasion by subconjunctival fibroblasts which penetrate the cornea along natural tissue planes. Indeed, as pointed out above, a similar histology can be seen in the articles by Cllova-Atanasova ${ }^{2}$ and Barraquer. ${ }^{3}$ But these observers either have not recognised the fibroblasts or have concentrated on the degenerative connective tissue. In this regard I believe it important when examining a pterygium histologically to pay particular attention to the orientation of the specimen. The junction of the cap and head is marked by change from corneal to conjunctival type epithelium, and this is the area that must be carefully explored if one wishes to reveal the essential histology of a pterygium.

Those observers who concentrated on the degeneration of the elastic and collagen fibres have in my opinion concentrated on the wrong end of the pterygium. There is no doubt that degenerative changes are seen, but in my opinion they do not constitute the essential pathology.

Barraquer $^{3}$ and other authors lay great stress on fluorescein staining of the raised limbal conjunctival tissue and the adjoining cornea, but, at least in this part of the world, no frank staining as shown in his article is seen. There is occasional punctuate staining, but this could be due to the mechanical friction of the 


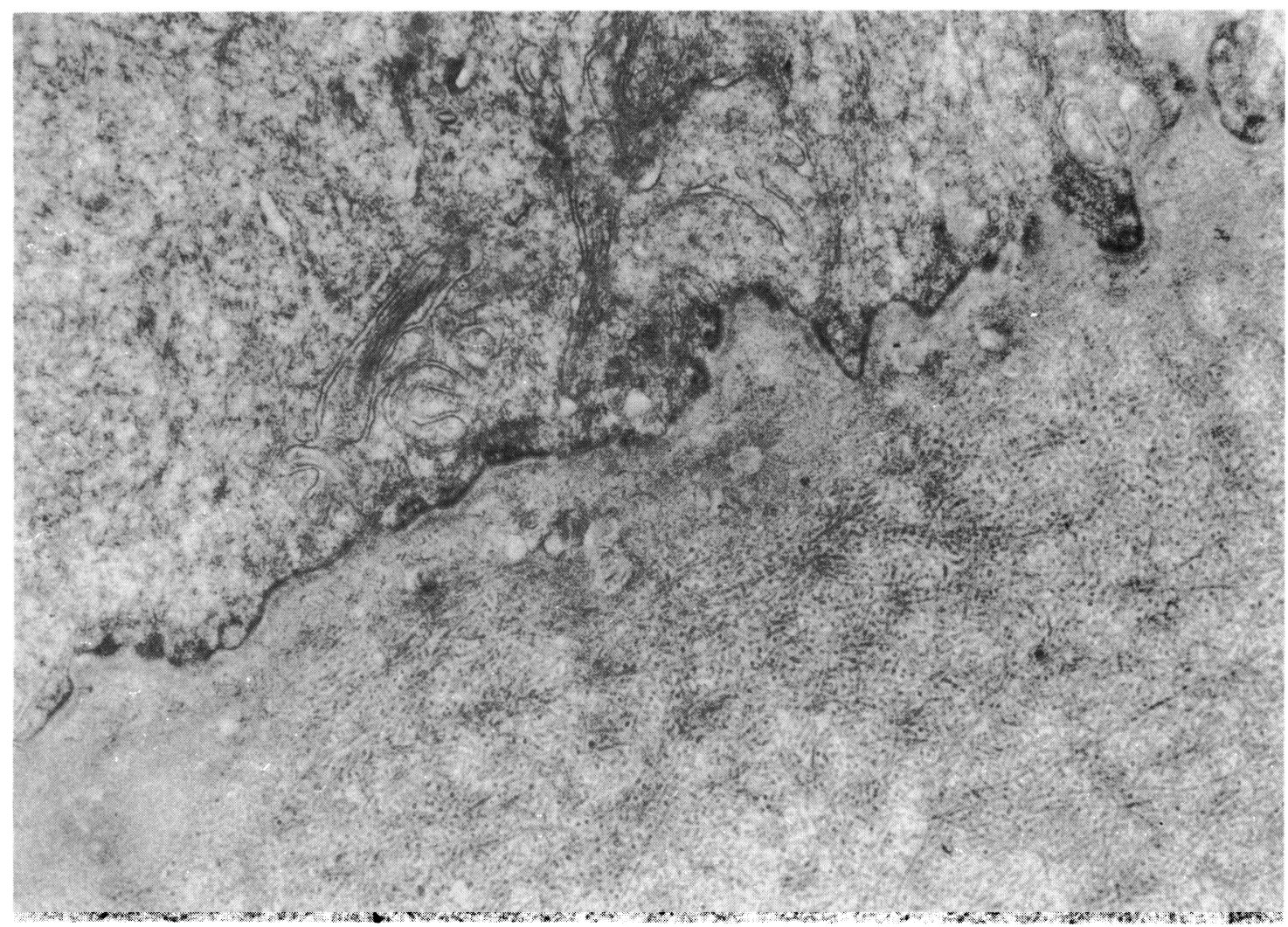

Fig. 4 Normal appearing basal cell membrane, basement membrane, and Bowman's layer immediately central to the cap. $(\times 23000)$.

lids denuding the raised uneven surface epithelium.

If one accepts the degenerative or inflammatory theories, how does one explain the often rapid recurrence in a few months of a pterygium? On the other hand if a fibroblastic cell invasion of the cornea is considered to be the essential pathology, then a recurrence could be ascribed to the same cause, namely, an accelerated reinvasion of the cornea.

The primary invasion of the cornea (but not the recurrence) is thought to be produced by the photobiological effect of ultraviolet (UV) light in the wavelengths $320-290 \mathrm{~nm}^{1}{ }^{1}$ Blum $^{10}$ has produced much evidence of neoplasia and hyperplasia of cells in mice by the action of UV light, and it is now also generally accepted, at least in the skin, that this is the most important nuclear damaging agent. It is proposed that fibroblasts whose deoxyribonucleic acid has been altered by UV light multiply and become invasive, producing over the years the characteristic picture of pterygium. The elastic and collagen degeneration is produced also by the affect of UV light on the subconjunctival tissue, but I do not regard this as being the important histological finding in pterygium.

The recurrence would appear to have no relationship to UV light. It occurs rapidly in most cases and often with the patient wearing protective glasses against UV light. It would appear to be due to an accelerated fibroblastic proliferation produced by the trauma of operation much in the same way as the production of keloid tissue. The concept, then, of fibroblastic proliferation and invasion adequately explains the clinical appearance and behaviour of a pterygium and, as shown above, has some histological support.

\section{References}

1 Cameron ME. Pterygium throughout the world. Springfield: Thomas, 1965.

2 Cllova-Atanasova B. Histological and histochemical changes of epithelium, basal membrane and Bowman's membrane in the avascular corneal part of pterygium. Folia Med 1968; 10: 23-6.

3 Barraquer JI. Etiologia y patogenia del pterigion y de las excavaciones de la cornea de Fuchs. Arch Soc Oftalmol HispanoAm 1964; 5: 49-60.

4 Vass Z, Tapaszto. The histochemical examination of the fibres of 
pterygium by elastase. Acta Ophthalmol (Kbh) 1964; 42: 849-54.

5 Hogan JM, Alvarado J. Pterygium and pinguecula: electron microscopic study. Arch Ophthalmol 1967; 78: 174-86.

6 van der Zypen F, van der Zypen E, Daicker B, Zur Ultrastruktur des Pterygium (1 \& 11). Albrecht von Graefes Arch Klin Ophthalmol 1975; 193: 161-87.

7 Ansari MW, Rahi HS, Shukla BR. Pseudoelastic nature of pterygium Br J Ophthalmol 1970; 54: 473 -6.
8 Akamatu Y, Sugita Y. Studies on the pterygium. Report VI. Histochemical studies. Nippon Ganka Gakkai Zasshi 1969; 73: 1046-52.

9 Lemercier G, Cornand G, Burckhart M-F. Pinguecula et pterygion: étude histopathologique et ultrastructurale. Virchows Arch (Pathol Anat) 1978; 379: 321-33.

10 Blum HF. Carcinogenesis by ultraviolet-light. Princeton: Princeton University Press, 1959. 